\title{
Aggravation of cyclophosphamide-induced reproductive toxicity in mice by aqueous extract of Aegle marmelos (L.)
}

\author{
Sangita Singh¹, Awadhesh Kumar Mishra², Swarn Lata ${ }^{1 *}$, Kavindra Nath Tiwari ${ }^{2 *}$ \\ ${ }^{I}$ Department of Zoology, MMV, Banaras Hindu University, Varanasi, U.P, India, ${ }^{2}$ Department of Botany, MMV, Banaras Hindu \\ University, Varanasi, U.P, India
}

\begin{abstract}
Aegle marmelos (L.) (Rutaceae) commonly known as bael is an important medicinal fruit tree. The present study focused on the effects of aqueous extract of Aegle marmelos (AEAM) on the testis and sperm characteristics induced by cyclophosphamide (CPA) in mice. Thirty six adult Parke's strain mice were divided into six groups: group I given only distilled water (control); group II administered with AEAM alone once in a week for five weeks; group III administered with CPA ( $200 \mathrm{mg} / \mathrm{kg}$ b.w., intraperitoneally) once in a week for five weeks and group IV-VI CPA along with AEAM (400, 500 and $600 \mathrm{mg} / \mathrm{kg}$ b.w., orally). CPA was found to reduce gonadosomatic index (GSI), sperm counts, motility, viability, antioxidant activities and induced histopathological changes of testis. In the group administered AEAM with CPA an exacerbation of sperm count, motility and viability of the cauda epididymis, GSI, antioxidant activities and architecture of testis was observed. The results suggest that the administration of AEAM may aggravate CPA-induced reproductive toxicity. It may be helpful in preparation of natural male contraceptives.
\end{abstract}

Keywords: Aegle marmelos (L.)/extract/effects/sperm. Cyclophosphamide. Gonadosomatic index (GSI). Reproductive toxicity. Spermatozoa.

\section{INTRODUCTION}

Cyclophosphamide (CPA) is widely used for treatment of cancer diseases. It is also used as chemotherapeutic agent in various malignancies. It is used to cure various autoimmune disorders such as systemic lupus erythematosus, multiple sclerosis and also used as an immunosuppressive drug. It is well known immunosuppressive agent for organ transplantation, multiple sclerosis, systemic lupus erythematosus and other benign diseases (Dollery, 1999). The active metabolite of CPA acts as an alkylating agent, which facilitates the attachment of the alkyl group to the purine base particularly acts on the $7^{\text {th }}$ position nitrogen atom on the imidazole ring of the guanine base. The alkylating purine base inhibits the DNA replication by the formation of inter strand cross linking in the DNA strand, and thus inhibit the normal cell division process

\footnotetext{
*Correspondence: S. Lata. Department of Zoology, MMV, Banaras Hindu University, Varanasi, 221005, U.P, India. Tel.: +91 9415301826. Fax: +91 5422367927. E-mail: swarnlatabhu12@mail.com. K. N. Tiwari. Department of Botany, MMV, Banaras Hindu University, Varanasi, 221005, U.P, India. Tel.: +91 9335668374. Fax:+91 5422367927. E-mail: kntiwaribhu@gmail.com
}

in rapidly proliferating cells (Higuchi et al., 2001). The reproductive toxicity of CPA has been reported in several animals including the human being. In spite of side effects, CPA still has been reported for various clinical applications for the prevention of cancer (Das et al., 2002). The adverse life-threatening effect of CPA is well known in the adult male patients. The adverse effects are low sperm count and motility (Jalali, Hasanzadeh, Malekinejad, 2012; Maremanda, Khan, Jena, 2014; Cao et al., 2017), nonfunctional of normal spermatogenic cycle in testis as well as permanent infertility at higher doses (Howell, Shalet, 1998; Yuan et al., 2014). The longterm treatment with CPA is related to loss in the weight of reproductive organs which leads to infertility (Trasler, Hales, Robaire, 1986; Comish et al., 2014). The male cancer patients treated with CPA exhibited increased incidence of azoospermia as well as oligospermia (Kenney et al., 2001) side by side multiple low dose treatment with CPA results the post implantation loss, high risk of premature menopause in the female, malformed and growth retardation in the fetus of the rat. Aegle marmelos belong to family Rutaceae, commonly known as the bael fruit tree (Singh, Chaturvadi, 
1981). It is an important medicinal plant, native of India and found all over the sub Himalayan forests. The fruits of this plant are smooth with green, hard peel when immature and yellow peel color on maturation. The fibrous yellow pulp is aromatic, pleasant and sweet in test. All parts of the tree have various medicinal properties (Chanda et al., 2008). The important bioactive constituent were isolated from this plant is lupeol, aegelin, citronella, marmesinine, cumin aldehyde, citral, cineol, skimmianine, eugenol (Maity et al., 2009). These constituent are used for the cure of various diseases including diarrhea, jaundice, swollen joints, fractures, anemia, wound healing, asthma as well as for the control of high blood pressure (Pushpendra et $a l ., 2012)$.The volatile oils and pectins were obtained from this plant which are used as an ingredient in the numerous pharmaceutical products. The wood-ash is rich in minerals and is used as ingredient in products like squash, coffee and candy etc. A. marmelos has been reported to have antiproliferative activity, anti-pyretic, hypoglycemic, antidiarrheal, anti-inflammatory and antioxidant properties (Narender et al., 2007).

Due to wide range of medicinal applications and antioxidant properties of $A$. marmelos, in the present study, we have investigated the effect of aqueous extracts of $A$. marmelos (AEAM) on CPA-induced changes in sperm characteristics and testicular oxidative damage in mice.

\section{MATERIAL AND METHODS}

\section{Drug and chemicals}

CPA was obtained from Sigma Aldrich Ltd., New Delhi, India. The other chemicals and solvents used were of the highest purity of analytical grade.

\section{Plant material}

The leaves of $A$. marmelos were collected from the campus of Banaras Hindu University, Varanasi, India during the months of September - December and were authenticated by Prof. N. K. Dubey, Department of Botany, Banaras Hindu University, Varanasi. A voucher specimen (Rutaceae /2014/1) was kept in the departmental herbarium for future reference.

\section{Preparation of aqueous extract of Aegle marmelos (AEAM)}

Fresh leaves were washed under running tap water, dried in shade at room temperature for a week and powdered mechanically. The powder (100 grams) was added in $400 \mathrm{~mL}$ deionized water under stirring at room temperature $\left(25 \pm 2{ }^{\circ} \mathrm{C}\right)$. The aqueous extraction was done followed the method of Faremi et al. (2008). After extraction, total filtrate was centrifuged at 5,000 rpm to separate the supernatant. The supernatant was concentrated to dryness in rotary vacuum evaporator at $45{ }^{\circ} \mathrm{C}$. The dry extract was collected and stored in a refrigerator at $4{ }^{\circ} \mathrm{C}$ for further use.

\section{Animal model}

All the experiments were performed in accordance with institutional practice and within the framework of revised animals (Committee for the Purpose of Control and Supervision of Experiments on Animals; CPCSEA) Act of 2007 of Govt. of India on animal welfare. The study was approved by the Ethical Committee of the Faculty of Science, Banaras Hindu University, Varanasi (No. F.Sc./IAEC/2014-15/0335; Dated17.10.2014). The study was conducted on adult male Parke's strain mice $(30 \pm 3 \mathrm{~g})$, which were obtained from Department of Zoology, Banaras Hindu University, Varanasi, India. The animals were fed with commercially available standard mice pellet feed and water was provided ad libitum. Mice were housed under conditions of controlled temperature $\left(25 \pm 2{ }^{\circ} \mathrm{C}\right)$ and acclimatized to a $12 \mathrm{~h} \mathrm{light} / 12 \mathrm{~h}$ dark cycle.

\section{Experimental design}

Animals were divided into six groups of six mice each and the treatment was done as shown below:

Group I: Control mice received distilled water (intraperitoneally) once in a week for 5 weeks.

Group II: AEAM $(600 \mathrm{mg} / \mathrm{kg}$ bw, orally $)$ once in a week for 5 weeks.

Group III: CPA $200 \mathrm{mg} / \mathrm{kg}$ bw, for 5 weeks (once in a week) by intraperitoneal injection (The dose of cyclophosphamide was selected based on earlier studies as $200 \mathrm{mg} / \mathrm{kg}$ b.w (El-Naggar et al., 2015).

Group IV: CPA (200 mg/kg bw, intraperitoneally) and AEAM (400 mg/kg bw) orally for 5 weeks (once in a week).

Group V: CPA (200 mg/kg bw, intraperitoneally) and AEAM $(500 \mathrm{mg} / \mathrm{kg} \mathrm{bw})$ orally for 5 weeks (once in a week).

Group VI: CPA (200 mg/kg bw, intraperitoneally) and $\operatorname{AEAM}(600 \mathrm{mg} / \mathrm{kg} \mathrm{bw})$ orally for 5 weeks (once in a week). 


\section{Preparation of tissues}

At the end of the treatment period mice were sacrificed by cervical dislocation. The testis was removed, cleared of the adhering tissues, washed with ice-cold saline immediately, dried on tissue paper, weighed and frozen for the antioxidant assays.

\section{Gonadosomatic index (GSI) evaluation}

GSI is the calculation of the gonad mass as a proportion of the total body mass. It is calculated using the following formula:

GSI $=($ Gonad weight $/$ total body weight $) \times 100$

\section{Sperm parameters}

The motility, viability and count of spermatozoa in the cauda epididymis were assessed as per WHO Laboratory Manual (WHO, 2010). Data were obtained from all the six animals of each group.

\section{Antioxidants in testis}

For antioxidant assays, the tissue homogenate was prepared in ice cold phosphate buffer saline (PBS) $(0.1 \mathrm{M}, \mathrm{pH} 7.4)$ and centrifuged at $5,000 \mathrm{rpm}$ at $4{ }^{\circ} \mathrm{C}$ for $30 \mathrm{~min}$. The supernatant was quantified for the assay of malondialdehyde (MDA), superoxide dismutase (SOD) and catalase (CAT) were performed with commercially available diagnostic kits (Sigma-Aldrich, New Delhi, India).

\section{Histopathological studies}

The testis was blotted free of mucus. The tissues were washed in normal saline, cut into pieces of desired size and fixed in aqueous Bouin's solution for $12 \mathrm{~h}$. After fixation, the tissues were cleaned, dehydrated through a gradual series of alcohol and then processed for paraffin embedding. Tissue sections of $5 \mu \mathrm{m}$ in thickness were mounted on slides and stained with hematoxylin and eosine for photomicroscopic observations.

\section{Statistical analysis}

The results were expressed as Mean $\pm \mathrm{SE}(\mathrm{SEM})$, analyzed through one-way ANOVA, followed by the post hoc Dunnett's test for comparison of various treatments using the SPSS 16.0. Differences were considered statistically significant at $p<0.05$.

\section{RESULTS}

\section{Effect of AEAM on the gonadosomatic index (GSI) against CPA-induced toxicity in mice}

GSI is the calculation of the gonad mass as a proportion of the total body mass. It is a tool for measuring the sexual maturity of animals in correlation to testis development. The treatment of male mice with CPA caused a significant $(p<0.001)$ loss in the GSI compared with the control group (Figure 1). The treatment of CPA $+\operatorname{AEAM}(400,500$ and $600 \mathrm{mg} / \mathrm{kg})$ caused a significant decrease $(p<0.001)$ in GSI.

\section{Effect of AEAM on the sperm parameters against CPA-induced toxicity in mice}

The effect of CPA and co-administration of AEAM on epididymal sperm count, sperm motility and sperm viability are presented in Figure 1. There is significant decrease $(p<0.001)$ in sperm count, sperm motility and sperm viability in mice exposed to CPA-treated group as compared to the control. In AEAM treated mice the cauda epididymal sperm parameters showed evidence of dose dependent toxicity. At higher dose of AEAM $(600 \mathrm{mg} / \mathrm{kg})$, the sperm count, motility and viability were very much reduced when compared to the lower doses (400 and 500 $\mathrm{mg} / \mathrm{kg}$ ) treated group as well as control group.

\section{Effect of AEAM on the antioxidants activity in testis against CPA- induced toxicity in mice}

Intoxication of mice with CPA was followed by a significant decrease $(p<0.001)$ in antioxidant enzyme activities such as SOD and CAT in the testis (Figure 2). Results revealed that CPA-treated mice have significantly higher $(p<0.001)$ level of malondialdehyde (MDA) in relation to the control mice. On the other hand, there was a decline in the activity of antioxidant enzymes with AEAM treatment in comparison to control group. In AEAM alone administration showed significant changes when compared with control group, it indicates its adverse effects.

\section{Histopathological study of testis}

The spermatogonia, spermatocytes, spermatids and spermatozoa could be clearly identified in the seminiferous tubules (Figure 3). The well preserved Sertoli cells and tubular basement membrane were observed in group I (control). However, in the CPA-treated group, differences were observed in histopathology of testis such as complete 

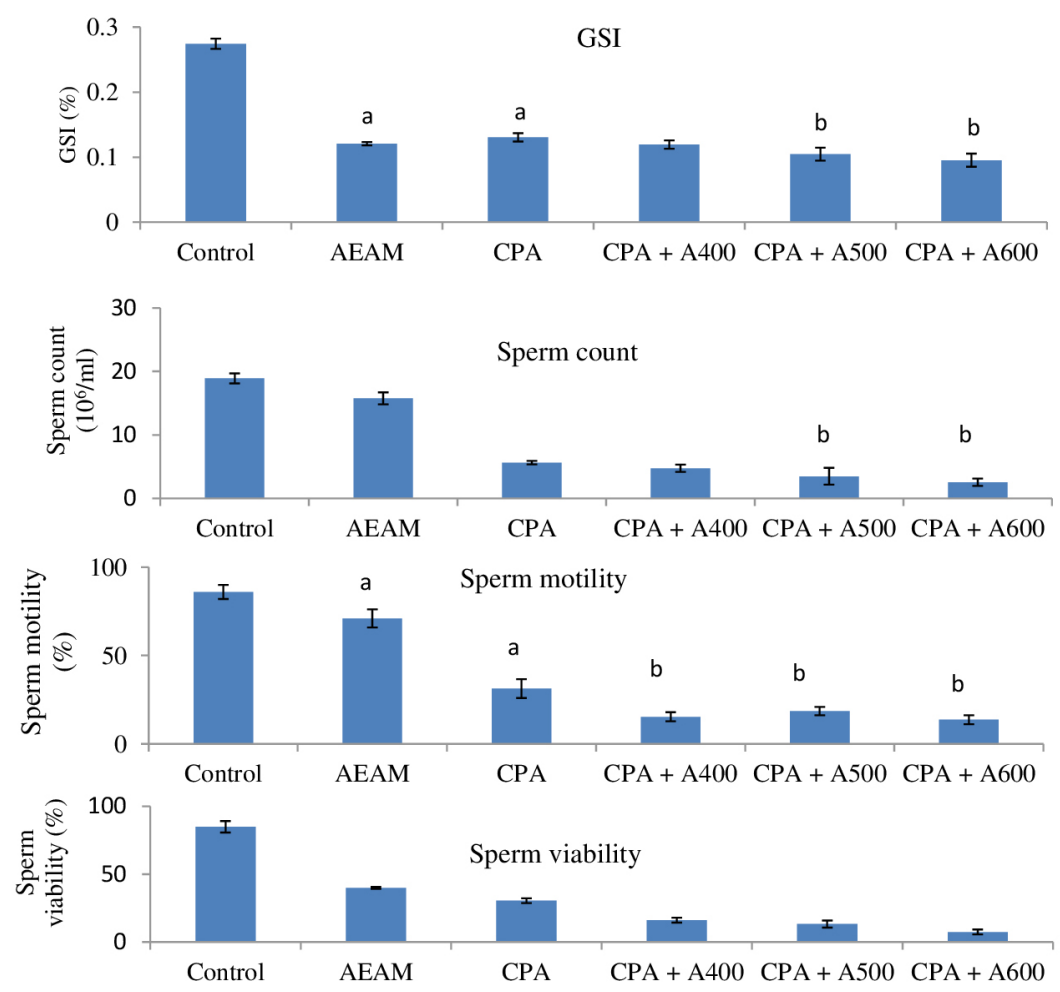

FIGURE 1 - Effect of aqueous extract of A. marmelos on CPA-induced toxicity on GSI, Sperm count, Sperm motility and Sperm viability. Each bar represents the Mean $\pm \mathrm{SE}, \mathrm{n}=6$; ' $\mathrm{a}$ ' indicates the significant difference between the control and CPA treated groups, ' $\mathrm{b}$ ' indicates the significant difference between the CPA treated and AEAM treated groups. Significant at $p<0.001$.
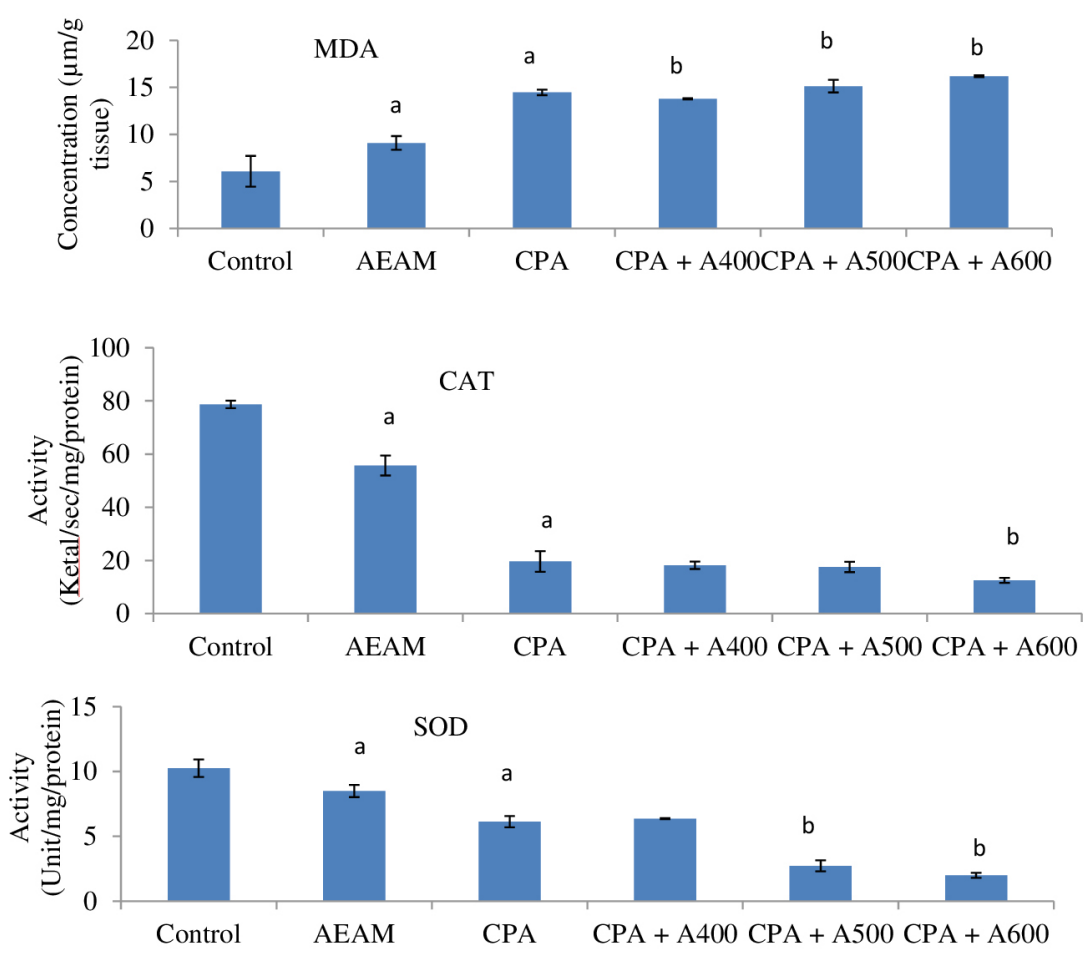

FIGURE 2 - Effect of aqueous extract of A. marmelos on CPA-induced toxicity on the activities of MDA, SOD and CAT were carried out in testis. Each bar represents the Mean $\pm \mathrm{SE}, \mathrm{n}=6$; ' $\mathrm{a}$ ' indicates the significant difference between the control and CPA treated groups, ' $\mathrm{b}$ ' indicates the significant difference between the CPA treated and AEAM treated groups. Significant at $p<0.001$. 


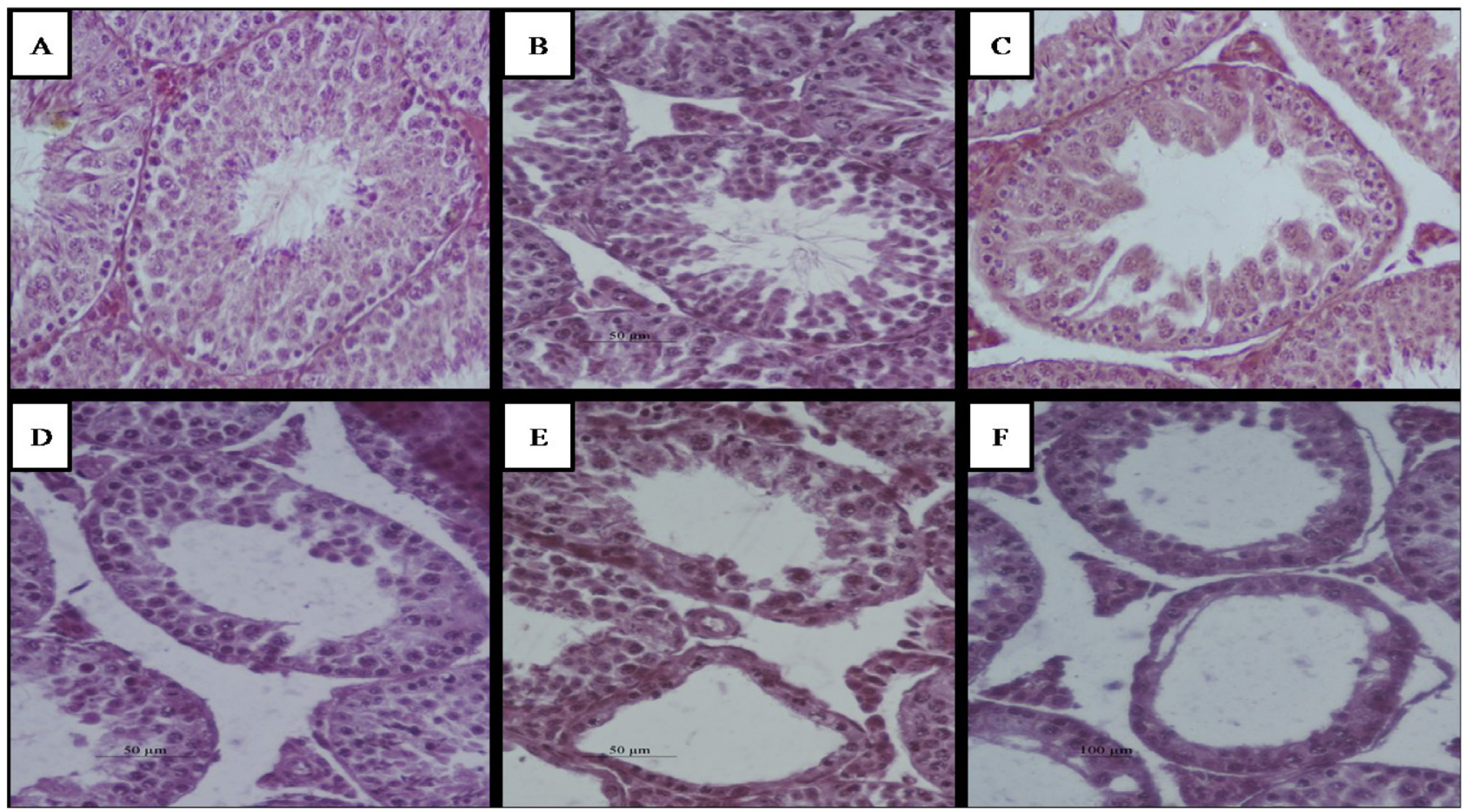

FIGURE 3 - Representative photomicrographs of testis sections (400X: H\&E). The testis section from control mice evidenced different stages of spermatogenesis (A). In the AEAM treated testis showed alterations in spermatogenesis (B). CPA treated mice testis showed atrophy of seminiferous tubules, degenerated germ cells and shrunken seminiferous tubules, compared with the normal cellular content of the control group (C). In the CPA + AEAM showed, the damage to the seminiferous tubules was considerably more severe (D-F).

atrophy of seminiferous tubules, degenerated germ cells, shrunken seminiferous tubules and widening of interstitial space (group III). This indicates that, the testis tissues were damaged by CPA as compared with the normal architecture of the control group. In contrast, marked degenerative changes were observed in the histoarchitecture of the testis in CPA + AEAM-treated mice (group IV to VI), showing disorganization and decreased amount of mature spermatozoa in seminiferous tubules as compared to control. In lower dose $(400 \mathrm{mg} / \mathrm{kg})$ group, seminiferous tubules exhibited active spermatogenesis, but there were loosening of germinal epithelium in seminiferous tubules (group IV). By contrast, marked alterations were noticed in testis of mice treated with higher doses of the AEAM. Intraepithelial vacuolation, loosening of germinal epithelium, marginal condensation of chromatin in round spermatids and degeneration of cell types were observed in the seminiferous tubules of AEAM treated (500 and $600 \mathrm{mg} / \mathrm{kg}$ ) mice (group V and VI).

\section{DISCUSSION}

It is evident from the results that the mice treated with AEAM along with CPA brought about significant loss in GSI, which is related to the number of spermatids and spermatozoa in the testes. Oral administration of AEAM in male mice caused a decrease in the GSI which could be attributed to the loss of germ cells (D'Souza, Narayana, 2001). The decrease in the GSI might be due to very low level of steroidal hormone (androgen), which was not enough to retain the weight of gonads (Anitha et al., 2013). The decreasing weight of the reproductive organs in the AEAM-treated male mice clearly indicates the extract caused functional and structural changes in the testes (Banerji, Adhikary, Chatterjee, 2000).

The sperm count, viability and motility in the cauda epididymis were adversely affected by the CPA + AEAM treatment. It is known that the structure and function of the epididymis is dependent on steroidal hormone androgens (Cooper, 1992). In the present study, a dosedependent suppression of cauda epididymal sperm count, viability and motility reflects the restriction of supply of testosterone to epididymis which caused impaired epididymal function. This impairment may also be due to the reduced activity of the testis, which disturbed the usual passage of testicular fluid into the epididymis (Ansari et al., 1998). It is also confirmed by reduced GSI. The treatment with AEAM may possibly inhibited the 
action of ATP in spermatozoa by inhibiting the oxidative phosphorylation in the respiratory chain and prevent the phosphorylation of ADP to ATP (Sharma, Jacob, 2002). Thus due to scarcity of high energy rich compound ATP, results the lacking in the movement of spermatozoa. Insufficient concentration of the spermatozoa as well as immobility inhibits the penetration of cervical mucus and thus failed to fertilize the ova (Lohiya, Goyal, 1992). The reduction in sperm parameters in cauda epididymis is an importance with regards to fertilization.

It is revealed that the activity of CAT and SOD in $\mathrm{CPA}+\mathrm{AEAM}$ treated groups were decreased along with the elevation in testicular MDA level in comparison to the control. The reduced level of CAT and SOD might be due to the excessive production of harmful free radical and anions in response to the aqueous extract of $A$. marmelos. It may be that an increased rate of ROS production may hinder the action of antioxidant enzymes. The decreased expression of these antioxidant enzymes may cause increased oxidative stress (Anitha et al., 2013) protects dehydratases against free radicals, superoxide and low CAT activity, closely relates to low motility of ejaculated spermatozoa (Kawakami et al., 2007). AEAM showed antitesticular activities by inhibiting the normal pituitary gonadotropin secretion. The extract has direct effect on spermatogenic cell and testicular tissue for induction of oxidative injury that may suppress the testicular gametogenic and steroidogenic activities (Das et al., 2009). Testicular MDA levels were considerably increased in CPA + AEAM treated groups. The increased MDA level by AEAM through the production of free radicals causes a disturbance in the antioxidant status of the testis. The lipid composition of the sperm membrane exerts a considerable effect upon the functional quality of spermatozoa (Zalata et al., 1998).

Histological observations showed that CPA + AEAM treatment disrupted the seminiferous tubule architecture. In AEAM treated mice, most of the seminiferous tubules were azoospermic. The affected seminiferous tubules showed intraepithelial vacuolation, loosening of germinal epithelium and mixing of spermatids of different stages of spermatogenesis. Similar histological changes have been reported in testis of mice after treatment with aqueous leaf extracts of Allamanda cathartica, Azadirachta indica and hexane extract of flower buds of Syzygium aromaticum and several other antispermatogenic agents such as nitrofurazone, gossypol tetra-acetic acid and SC 12937 (Singh, Chakravarty, 2003).

Furthermore, the treatment also caused substantial reductions in the diameter of the seminiferous tubules of the germinal epithelium in testis of extract-treated mice compared to control group. These observations indicate the adverse effect of the treatment on spermatogenesis.

Alterations in the sperm parameters and histopathological examination of testis suggested a disturbed testicular and epididymal tissue due to AEAM treatment. Extract affects the sex organs due to presence of specific compounds like coumarine which is selectively stored in the sex organs. It is well established that active sperm motility is essential to achieve the successful fertilization. There are millions of spermatozoa ejaculated into the vagina must reach to the ovum for fertilization in the fallopian tube by penetrating the cervical mucus and passing through the uterine cavity. Presence of adequate number of spermatozoa possessing normal function are necessary for successful fertilization, due to deviation in sperm physiology and function leads to infertility (Daniel, Angela, Walter, 2011).The results of this investigation showed that treatment with aqueous extract of $A$. marmelos, inhibits the sperm motility in mice. This inhibition coincides with a gradual and significant decline in cauda epididymal sperm count and percentage of viable spermatozoa.

In our previous report (Singh, Lata, Tiwari, 2014), the primary screening of aqueous extract of leaf of $A$. marmelos revealed the presence of phenols, tannins, flavonoids, saponin and alkaloids in the extract. GS-MS analysis of the extract confirmed the presence of several compounds which have antioxidant potential. Several other compounds were also present which showed antiinflammatory (Arul, Miyazaki, Dhananjayan, 2005), anticancer (Jagetia, Venkatesh, Baliga, 2005) and hepatoprotective actions (Kuncha, Thirunavukkarasu, 2011). Extract affects the sex organs and fertility of organism might be due to presence of coumarin, which is selectively stored in the sex organs. Presence of coumarin caused the selective inhibition of the calcium channels (Nugroho et al., 2011).This calcium channels blockage might be a vital mechanism through which AEAM is acting as spermicidal agent. Role of calcium channels is concerned in the sperm viability as it mediate acrosomal reaction of human sperm during fertilization and inhibitors of these channels may prevent sperm-egg fusion (Enders, 1997). Alternatively the plant may be exploited for use as an 'antifertility drug'.

The effect of AEAM has been investigated against CPA-induced toxicity in testis. The results of administration of different doses of AEAM with CPA showed testicular damage and spermicidal activity. Therefore, it may be concluded that AEAM increased the damage caused by CPA. 


\section{CONCLUSION}

Oral administration of AEAM to male mice caused a decreased in the GSI which could be attributed to the loss of germ cells. The decrease in the weight of the reproductive organs in the AEAM-treated male mice clearly indicates that the extract caused structural and functional alteration in the testes. The activity of SOD and CAT in CPA + AEAM treated groups were decreased along with the elevation in testicular MDA level in comparison to the control. The reduced level of SOD and CAT might be due to the excess production of anions in response to the aqueous extract of $A$. marmelos. It revealed from the results that the administration of AEAM may aggravate CPA-induced reproductive toxicity. Male reproductive toxicity induced by the plant extract can be used for clinical trial for the possibility of the development of natural product based male contraceptives.

\section{ACKNOWLEDGEMENT}

The financial assistance in the form of SRF to Sangita Singh from the University Grant Commission, New Delhi, is gratefully acknowledged.

\section{REFERENCES}

Anitha M, Sakthidevi G, Muthukumarasamy S, Mohan V. Evaluation of anti-fertility activity of ethanol extract of Cynoglossum zeylanicum (vehl ex hornem) thumb. ex lehm (boraginaceae) whole plant on male albino rats. J Curr Chem Pharma Sci. 2013;3(2):135-145.

Ansari AS, Kumar Y, Srivastava S, Lohiya NK. Long-term sequelae of tolnidamine on male reproduction and general body metabolism in rabbits. Contraception. 1998;57(4):271-279.

Arul V, Miyazaki S, Dhananjayan R. Studies on the antiinflammatory, antipyretic and analgesic properties of leaves of Aegle marmelos Corr. J Ethnopharmacol. 2005;96(1-2):159163.

Banerji J, Adhikary P, Chatterjee A. The reversible antifertility effect of Piper beetle Linn. on Swiss albino male mice. Contraception. 2000;62(5):271-274.

Cao Y, Wang X, Li S, Wang H, Yu L, Wang P. The effects of 1-carnitine against cyclophosphamide-induced injuries in mouse testis. Basic Clin Pharmacol Toxicol. 2017;120(2):152-158.
Chanda R, Ghosh A, Mitra T, Mohanty JP, Bhuyan N, Pawankar G. Phytochemical and pharmacological activity of Aegle marmelos as a potential medicinal plant: an overview. The Int J Pharm. 2008;6:3.

Comish PB, Drumond AL, Kinnell HL, Anderson RA, Matin A, Meistrich ML, Shetty G. Fetal cyclophosphamide exposure induces testicular cancer and reduced spermatogenesis and ovarian follicle numbers in mice. PLoS One. 2014;9(4):e93311.

Cooper TG. The epididymis as a site of contraceptive attack. In: Nieschlag E, Habenicbt UF, editors. Spermatogenesis, fertilization, contraception. Berlin: Springer; 1992. p. 419-460.

D'Souza UJA, Narayana K. Introduction of seminiferous tubular atrophy by single dose of 5- fluorouracil (5-FU) in Wistar rats. Indian J Physiol Pharmacol. 2001;45(1):87-94.

Daniel EH, Angela PC,Walter CM. A common mutation in the defensin DEFB126 causes impaired sperm function and sub fertility. Euro Urol. 2011;60:1304-1305.

Das UB, Mallick M, Debnath JM, Ghosh D. Protective effect of ascorbic acid on cyclophosphamide-induced testicular gametogenic and androgenic disorders in male rats. Asian J Androl. 2002;4(3):201-207.

Das UK, De D, Chatterjee K, Mallick C, Bera T K, Ghosh D. Antigonadal effect induced by hydro-methanolic extract of leaf of Aelgle mermelos in male rat: effect of hCG co-administration. J Med Plants Res. 2009;3(10):728-735.

Dollery C. Therapeutic drugs. Edinburgh: Churchill Livingstone; 1999. p. 349-354.

El-Naggar SA, Alm-Eldeen AA, Germoush MO, El-Boray KF, Elgebaly HA. Ameliorative effect of propolis against cyclophosphamide induced toxicity in mice. Pharm Biol. 2015;53(2):235-241.

Enders G. Clinical approaches to male infertility with a case report of possible nifedipine-induced sperm dysfunction. J Am Board Fam Pract. 1997;10(2):131-136.

Faremi TY, Suru SM, Fafunso MA, Obioha UE. Hepatoprotective potentials of Phyllanthus amarus against ethanol-induced oxidative stress in rats. Food Chem Toxicol. 2008;46(8):26582664. 
Higuchi H, Nakaoka M, Kawamura S, Kamita Y, Kohda A, Seki T. Application of computer-assisted sperm analysis system to elucidate lack of effects of cyclophosphamide on rat epididymal sperm motion. J Toxicol Sci. 2001;26(2):75-83.

Howell S, Shalet S. Gonadal damage from chemotherapy and radiotherapy. Endocrinol Metab Clin North Am. 1998;27(4):927943.

Jagetia GC, Venkatesh P, Baliga MS. Aegle marmelos (L.) Correa inhibit proliferation of transplanted Earlich ascites carcinoma in mice. Biol Pharm Bull. 2005;28(1):58-64.

Jalali AS, Hasanzadeh S, Malekinejad H. Achillea millefoliumin florescence aqueous extract ameliorates cyclophosphamideinduced toxicity in rat testis: stereological evidences. Chin J Nat Med. 2012;10(4):247-254.

Kawakami E, Takemura A, Sakuma M, Takano M, Hirano T, Hori T, Tsutsui T. Superoxide dismutase and catalase activities in the seminal plasma of normospermic and asthenozoospermic beagles. J Vet Med Sci. 2007;69(2):133-136.

Kenney LB, Laufer MR, Grant FD, Grier H, Diller L. High risk of infertility and long term gonadal damage in males treated with high dose cyclophosphamide for sarcoma during childhood. Cancer. 2001;91(3):613-621.

Kuncha J, Thirunavukkarasu S. Hepatoprotective effect of Aegle marmelos (L.) Corr. leaf powder (crude) against carbon tetrachloride induced hepatic damage in albino rats. J Pharm Sci Res. 2011;3(7):1360-1363.

Lohiya NK, Goyal RB. Antifertility investigations on the crude chloroform extract of Carica papaya Linn, seeds in male albino rats. Indian J Exp Biol. 1992;30(11):1051-1055.

Maity P, Hansda D, Bandyopadhyay U, Mishra D K. Biological activities of crude extracts and chemical constituents of Bael, Aegle marmelos (L.). Corr Indian J Exp Biol. 2009;47(11):849861.

Maremanda KP, Khan S, Jena G. Zinc protects cyclophosphamide-induced testicular damage in rat: involvement of metallothionein, tesmin and Nrf2. Biochem Bioph Res Commun. 2014;445(3):591-596.

Narender T, Shweta S, Tiwari P, Papi Reddy K, Khaliq T, Prathipati $\mathrm{P}$, et al. Antihyperglycemic and antidyslipidemic agent from Aegle marmelos. Bioorg Med Chem Lett. 2007;17(6):1808-1811.
Nugroho AE, Anas Y, Arsito PN, Wibowo JT, Riyanto S, Sukari MA. Effects of marmin, a compound isolated from Aegle marmelos Correa, on contraction of the guinea pig-isolated trachea. Pak J Pharma Sci. 2011;24(4):427-433.

Pushpendra KP, Jyoti S, Lokesh S, Prajapati NK, Dubey B. Aegle marmelos: a review on its medicinal properties. Int J Pharm Phytopharmacol Res. 2012;1(5):332-341.

Sharma N, Jacob D. Assessment of reversible contraceptive efficacy of methanol extract of Mentha arvensis L. leaves in male albino mice. J Ethnopharmacol. 2002;80(1):9-13.

Singh KP, Chaturvadi GN. Determination of antiprotozoal activity in chronic dysentery from the pulp of Aegle marmelos. Sanch Ayu. 1981;8(2):34-40.

Singh S, Lata S, Tiwari KN. Aegle marmelos leaves protect liver against toxic effects of cyclophosphamide in mice. New York Sci J. 2014;7(9):43-53.

Singh SK, Chakravarty S. Antispermatogenic and antifertility effects of 20, 25-diazacholesterol dihydrochloride in mice. Repro Toxicol. 2003;17(1):37-44.

Trasler JM, Hales BF, Robaire B. Chronic low dose cyclophosphamide treatment of adult male rats: effect on fertility, pregnancy outcome and progeny. Biol Reprod. 1986;34(2):275-283.

World Health Organization. WHO. Laboratory manual for the examination and processing of human semen. 5 th ed. Geneva: WHO; 2010. 271 p.

Yuan D, Wang H, He H, Jia L, He Y, Wang T, Zeng X, Li Y, Li S, Zhang C. Protective Effects of total flavonoids from Epimedium on the male mouse reproductive system against cyclophosphamide-induced oxidative injury by upregulating the expressions of SOD3 and GPX1. Phytother Res. 2014;28(1):88-97.

Zalata AA, Christophe AB, Depuydt CE, Schoonjans F, Comhaire FH. White blood cells cause oxidative damage to the fatty acid composition of phospholipids of human spermatozoa. Int J Androl. 1998;21(3):154-162.

Received for publication on $18^{\text {th }}$ November 2016 Accepted for publication on $16^{\text {th }}$ February 2017 